\title{
Mariella Di Maio, La Matière d'Italie: Stendhal, Balzac
}

\section{Marco Stupazzoni}

\section{(2) OpenEdition}

\section{Journals}

\section{Edizione digitale}

URL: http://journals.openedition.org/studifrancesi/34842

DOI: 10.4000/studifrancesi.34842

ISSN: 2427-5856

\section{Editore}

Rosenberg \& Sellier

\section{Edizione cartacea}

Data di pubblicazione: 1 novembre 2005

Paginazione: 429

ISSN: 0039-2944

\section{Notizia bibliografica digitale}

Marco Stupazzoni, «Mariella Di Maio, La Matière d'Italie: Stendhal, Balzac», Studi Francesi [Online], 146

(XLIX | II) | 2005, online dal 30 novembre 2015, consultato il 18 avril 2021. URL: http://

journals.openedition.org/studifrancesi/34842 ; DOI: https://doi.org/10.4000/studifrancesi.34842

\section{Questo documento è stato generato automaticamente il 18 avril 2021.}

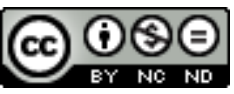

Studi Francesi è distribuita con Licenza Creative Commons Attribuzione - Non commerciale - Non opere derivate 4.0 Internazionale. 


\title{
Mariella Di Maio, La Matière d'Italie: Stendhal, Balzac
}

\author{
Marco Stupazzoni
}

\section{NOTIZIA}

MARIELla DI MAIO, La Matière d'Italie: Stendhal, Balzac, in Lingua, cultura e testo. Miscellanea di studi francesi in onore di Sergio Cigada, a cura di Enrica GALAZZI e Giuseppe BERNARDELLI, volume II, tomo I, Milano, Vita e Pensiero, 2003, pp. 395-408.

1 La matière d'Italie rappresenta uno degli assi portanti della scrittura narrativa di Stendhal e di Balzac: se nell'opera balzachiana, scrive M. Di Maio all'inizio di questo suo brillante contributo, il mito italiano «est surtout de l'ordre de l'écrit et de la création» e «se construit presque uniquement sur un système de prêts et d'emprunts culturels», in Stendhal, al contrario «le choix de l'italianité c'est le choix de devenir 'autre' pour devenir 'soi'» inglobando le influenze letterarie e le proprie esperienze personali in una sorta di «mythe de sa propre origine» (p. 395). In questo senso, risulta più che legittimo interrogarsi sulle cause dell'interesse verso l'Italia nutrito dai due romanzieri e appare ancor più fecondo indagare sulle modalità di restituzione narrativa de La matière d'Italie concentrando la propria attenzione su un corpus ben circoscritto ma altamente significativo di testi allo scopo di portare alla luce «des traits communs dans l'attitude des deux romanciers» verso l'Italia. Intimamente legato a un «désir de culture» e «de nature», la vocazione di raccontare l'Italia e gli Italiani assume, in Stendhal come in Balzac, un «caractère passéiste» (p. 391) che nasce da un rifiuto assoluto del presente storico e dell'attualità socio-politica. Nell'opera dei due scrittori, i modelli letterari e le istanze storico-politiche si intrecciano continuamente riflettendo i tratti della intensa «vocation intertextuelle» insita nel loto italianismo. Per entrambi, osserva l'autrice, la deriva sociale e politica dell'Italia "correspond à l'“inquiétante étrangeté" des Italiens qui, eux-mêmes, sont hors de l'Histoire» (p. 400). Grazie a Stendhal, il mito retrospettivo dell'Italia (e, in modo particolare, dell'Italia rinascimentale) informa e plasma il pensiero politico e sociale di Balzac e sarà proprio nell'articolo sulla 
Chartreuse de Parme del 1840 che si determinerà a pieno titolo, sotto il segno di Machiavelli, «l'aboutissement de son cheminement vers la matière d'Italie» (p. 408). 